\title{
Reduction of metastasis using a non-volatile buffer
}

\author{
Arig Ibrahim Hashim • Heather H. Cornnell • Maria de Lourdes Coelho Ribeiro • \\ Dominique Abrahams · Jessica Cunningham • Mark Lloyd • Gary V. Martinez • \\ Robert A. Gatenby $\cdot$ Robert J. Gillies
}

Received: 5 January 2011/Accepted: 28 July 2011 / Published online: 23 August 2011

(C) The Author(s) 2011. This article is published with open access at Springerlink.com

\begin{abstract}
The tumor microenvironment is acidic as a consequence of upregulated glycolysis and poor perfusion and this acidity, in turn, promotes invasion and metastasis. We have recently demonstrated that chronic consumption of sodium bicarbonate increased tumor $\mathrm{pH}$ and reduced spontaneous and experimental metastases. This occurred without affecting systemic $\mathrm{pH}$, which was compensated. Additionally, these prior data did not rule out the possibility that bicarbonate was working though effects on carbonic anhydrase, and not as a buffer per se. Here, we present evidence that chronic ingestion of a non-volatile buffer, 2-imidazole-1-yl-3-ethoxycarbonylpropionic acid (IEPA) with a $\mathrm{p} K_{\mathrm{a}}$ of 6.9 also reduced metastasis in an experimental PC $3 \mathrm{M}$ prostate cancer mouse model. Animals $(n=30)$ were injected with luciferase expressing PC3M prostate cancer cells either subcutaneously (s.c., $n=10$ ) or intravenously (i.v., $n=20$ ). Four days prior to inoculations, half of the animals for each experiment were provided drinking water containing $200 \mathrm{mM}$ IEPA buffer. Animals were imaged weekly to follow metastasis, and
\end{abstract}

Arig Ibrahim Hashim and Heather H. Cornnell, these authors contributed equally to this work.

A. Ibrahim Hashim $(\bowtie) \cdot$ H. H. Cornnell ·

M. L. Coelho Ribeiro - D. Abrahams .

J. Cunningham · G. V. Martinez ·

R. A. Gatenby · R. J. Gillies

Department of Cancer Imaging Research, H. Lee Moffitt Cancer

Center and Research Institute, 12902 Magnolia Dr,

Tampa, FL 33612, USA

e-mail: arig.ibrahimhashim@moffitt.org

M. Lloyd

Department of Analytic Microscopy Research, H. Lee Moffitt Cancer Center and Research Institute, 12902 Magnolia Dr,

Tampa, FL 33612, USA these data showed that animals treated with IEPA had significantly fewer experimental lung metastasis compared to control groups $(P<0.04)$. Consistent with prior work, the $\mathrm{pH}$ of treated tumors was elevated compared to controls. IEPA is observable by in vivo magnetic resonance spectroscopy and this was used to measure the presence of IEPA in the bladder, confirming that it was orally available. The results of this study indicate that metastasis can be reduced by non-volatile buffers as well as bicarbonate and thus the effect appears to be due to $\mathrm{pH}$ buffering per se.

Keywords Reduction of metastasis - Buffering · $\mathrm{pH} \cdot$ Acidic microenvironment $\cdot \mathrm{PC} 3 \mathrm{M}$.

Prostate cancer

\begin{tabular}{|c|c|}
\hline \multicolumn{2}{|c|}{ Abbreviations } \\
\hline FSEMS & $\begin{array}{l}\text { Fast spin echo multi slice; a pulse sequence } \\
\text { for use in } \mathrm{T}_{2} \text {-weighted magnetic resonance } \\
\text { imaging }\end{array}$ \\
\hline FOV & $\begin{array}{l}\text { Field of view used in magnetic resonance } \\
\text { acquisition }\end{array}$ \\
\hline IACUC & Institutional animal care and use committee \\
\hline IEPA & $\begin{array}{l}\text { 2-Imidazole-1-yl-3- } \\
\text { ethoxycarbonylpropionic acid }\end{array}$ \\
\hline MEM/EBSS & $\begin{array}{l}\text { Minimum essential media/Earle's balanced } \\
\text { salts }\end{array}$ \\
\hline MMP & Matrix metalloproteinase \\
\hline $\mathrm{MR} / \mathrm{I} / \mathrm{S}$ & Magnetic resonance imaging/spectroscopy \\
\hline OD & Outer diameter \\
\hline PBS & Phosphate buffered saline \\
\hline STEAM & $\begin{array}{l}\text { Stimulated echo acquisition mode; a varian } \\
\text { pulse sequence for localized magnetic } \\
\text { resonance spectroscopy }\end{array}$ \\
\hline TE/TR/TM & Echo time/repetition time/mixing time \\
\hline MR & Pulse sequence parameters \\
\hline
\end{tabular}

\section{Abbreviation} for use in $\mathrm{T}_{2}$-weighted magnetic resonance imaging acquisition

2-Imidazole-1-yl-3-

ethoxycarbonylpropionic acid

salts

Magnetic resonance imaging/spectroscopy

Outer diameter

Stimulated echo acquisition mode; a varian pulse sequence for localized magnetic resonance spectroscopy

MR Pulse sequence parameters 


\section{Introduction}

Acidosis is a common microenvironmental feature of most solid tumors [1]. Acidification of the extra cellular space is a consequence of high rates of glucose metabolism combined with inefficient tumor perfusion [2, 3]. Low extracellular $\mathrm{pH}$ can induce tumor cell migration, invasion and metastasis by poorly defined mechanisms [4, 5]. Acute exposure of cells to acidic $\mathrm{pH}$ has been shown to cause upregulation of several secreted proteases, such as cathepsins $\mathrm{D}, \mathrm{L}$, and/or B, [6-8] and increase expression of the matrix metalloproteinases (MMP); MMP-2 (gelatinase A) and MMP-9 (gelatinase B) in vitro [9, 10]. Additionally, pretreatment of melanoma cells with acidic $\mathrm{pH}$ before tail vein injection leads to increased experimental metastases in vivo $[11,12]$. We have shown previously that neutralizing the acid $\mathrm{pH}$ of tumors with oral $\mathrm{NaHCO}_{3}$ reduced spontaneous metastases without affecting systemic pH [13]. Mathematical reaction-diffusion type models were used to quantitatively describe the effect, thus providing a theoretical framework within which to interpret the data. The $\mathrm{p} K_{\mathrm{a}}$ of $\mathrm{NaHCO}_{3}$ in water is 6.14 [14]; and models predicted that the most efficacious buffers would have a $\mathrm{p} K_{\mathrm{a}}$ of 7.0. Additionally, the models assumed that bicarbonate was working as a buffer per se, and did not assume a specific interaction with carbonic anhydrases, which are used in vivo to dehydrate $\mathrm{HCO}_{3}{ }^{-}$. The current study was undertaken to test the efficacy of a non-bicarbonate/nonvolatile buffer with a higher $\mathrm{p} K_{\mathrm{a}}$ on tumor growth and metastases. For this, we have used a non-volatile buffer with a $\mathrm{p} K_{\mathrm{a}}$ of $\sim 6.9,2$-imidazole-1-yl-3-ethoxycarbonylpropionic acid (IEPA).

IEPA is a synthetic imidazole buffer that has been used to map the extracellular $\mathrm{pH}, \mathrm{pHe}$, in different animal models using magnetic resonance spectroscopic imaging, MRSI [15-17]. In this paper, we studied the effect of IEPA on spontaneous and experimental metastases. We first showed that oral IEPA was tolerable at doses up to $200 \mathrm{mM}$, as evidenced by animal weight gain. We demonstrated that IEPA was absorbed into the systemic circulation using MRS. Measurement of the $\mathrm{pH}$ in the primary subcutaneous tumor showed that IEPA slightly increased the tumor $\mathrm{pH}$. IEPA also had a moderate but statistically insignificant effect on the growth rate of the primary tumor, which was consistent with previous results using bicarbonate. We then observed that IEPA had a significant inhibitory effect on experimental metastases in the PC3M prostate model. Although the mechanism by which inhibiting metastases has not yet been determined, these data combined with the previous bicarbonate studies [14] demonstrate that non-volatile buffers are effective in reducing tumor metastases, and thus the effects appear to be due to buffering per se.

\section{Materials and methods}

Chemicals

IEPA (2-imidazole-1-yl-3-ethoxycarbonyl-propionic acid) was obtained from Dr. Paloma Ballesteros (Laboratory of Organic Synthesis and Molecular Imaging by Magnetic Resonance (Ref. Lab. 250) Faculty of Sciences, UNED $\mathrm{P}^{\circ}$ Senda del Rey, 9 28040-Madrid, Spain), and was dissolved in tap water at a concentration of $200 \mathrm{mM}$. The $\mathrm{pH}$ of the IEPA solution was adjusted to 7.4 (using $1 \mathrm{M} \mathrm{HCl}$ ) and then given to the mice to drink in place of their regular tap water. Cell culture media and supplies were obtained from Invitrogen, Carlsbad, CA. Luciferin was obtained from Gold Biotechnology, St. Louis, MO.

Animals housing and diet

All animals were maintained in accordance with IACUC standards of care in pathogen free rooms, in the Moffitt Cancer Research Center (Tampa, FL) Vivarium. All imaging and measurements were performed within the facility. Three days prior to inoculation with tumor cells, 4-6 week old male beige SCID mice (Harlan, Madison, WI) were placed in two cohorts per experiment, which were allowed to drink either tap water or $200 \mathrm{mM}$ IEPA. The weights of the water bottles were recorded before and after providing them to the animals, thereby tracking the amount of liquid consumed per cage. Animal weights were measured and recorded twice weekly, and the overall health of each animal was noted to ensure timely endpoints within the experiment.

\section{Cell culture and inoculation}

PC3M cells (-Luc6 clone) were obtained from Caliper (Hopkinton, MA). The cells were cultured using MEM/ EBSS media, supplemented with $10 \%$ fetal bovine serum, $1 \%$ penicillin streptomycin, $1 \%$ nonessential amino acids, $1 \%$ sodium pyruvate and $1 \%$ MEM vitamins. In preparation for inoculation into mice, the cells were trypsinized and rinsed once with sterile phosphate buffered saline (PBS) prior to resuspension at a concentration of $5 \times 10^{6}$ cells in $200 \mu \mathrm{l}$ PBS. For primary tumor injection, animals were prepared by removing the hair from the injection site, and $200 \mu \mathrm{l}$ containing $5 \times 10^{6}$ cells in PBS were injected subcutaneously into the right flank of each mouse. For experimental metastases, $200 \mu$ containing $5 \times 10^{6}$ cells in PBS were injected directly and slowly (over the course of $1 \mathrm{~min}$ ) into the tail vein of each mouse. In both preparations, cell distributions were verified by bioluminescent imaging immediately following injection. 


\section{Bioluminescent imaging}

Animals were anesthetized with isoflurane and injected intraperitoneally with $10 \mu \mathrm{l}$ per $\mathrm{g}$ body weight of sterile d-luciferin substrate prepared in PBS at $15 \mathrm{mg} / \mathrm{ml}$ (resulting dose $150 \mu \mathrm{g} / \mathrm{g}$ body weight). After $5 \mathrm{~min}$, mice were transferred to the thermo-regulated, light-tight chamber of the In Vivo Imaging System, IVIS-200 (Caliper; Hopkinton, MA). Photographic images were acquired first, and the bioluminescent images were overlaid on top of these images. Bioluminescent images were acquired by measuring photons emitted from luciferase-expressing cells and transmitted through the tissue. The exposure time for the bioluminescent image acquisition ranged from $0.5 \mathrm{~s}$ (whole tumor images) up to 2 min (lung metastases) to ensure nonsaturation, and differences in exposure time were corrected by expressing data as total flux in photons/sec, rather than photon counts. Images were analyzed using the LivingImage software (Caliper; Hopkinton, MA).

\section{Necrosis counting}

The center section $(\sim 5 \mathrm{~mm})$ of the subcutaneous tumor of each animal was fixed in paraffin blocks prior to staining one $4 \mu \mathrm{m}$ thick cross-sectional sample per animal with hematoxylin and eosin for histology. Histology slides were scanned using the Aperio $^{\text {TM }}$ (Vista, CA) ScanScope XT with a $20 \times / 0.8$ NA objective lens $(200 \times)$ at a rate of $2 \mathrm{~min}$ per slide via Basler tri-linear-array. Image analysis was performed using an Aperio Genie ${ }^{\circledR}$ v1 customized algorithm in conjunction with Positive Pixel Count v9 with the following optimized thresholds [Hue value $=0.2$; Hue width $=0.6 ;$ color saturation threshold $=0.05$; $\operatorname{IWP}($ High $)=210 ; \operatorname{Iwp}($ Low $)=\operatorname{Ip}($ High $)=160 ; \operatorname{Ip}($ low $)$ $=\operatorname{Isp}($ High $)=80 ; \quad \operatorname{Isp}($ Low $)=0]$. The algorithm was applied to the entire slide's digital image to determine the percentage of necrosis by detecting the number of pixels that satisfy the color and intensity specification defined above (necrotic), divided by the number of pixels in nonnecrotic tissue. The training algorithm developed above was quality controlled by a practicing pathologist.

Magnetic resonance imaging and spectroscopy

MR images and spectra were obtained on a Varian MR imaging spectrometer ASR310 (Agilent Life Sciences Technologies, Santa Clara, CA) with a $30 \mathrm{~cm}$ horizontal clear bore operating at a field strength of $7 \mathrm{~T}$. For reference, a high resolution spectrum of IEPA in $\mathrm{D}_{2} \mathrm{O}$ was obtained on a Varian Nuclear Magnetic Resonance spectrometer with a $54 \mathrm{~mm}$ vertical bore opening at a field strength of $9.4 \mathrm{~T}$. For in vivo spectroscopic imaging, naïve mice were allowed to drink IEPA for 3 days prior to imaging. The animals were sedated using isoflurane, placed in the animal cradle for insertion into the bore of the $7 \mathrm{~T}$ Varian MRI and maintained warm using a continuous warm air blower (Small Animal Instruments, Inc., Stonybrook, NY). Temperatures were measured using a fiber optic endorectal thermometer in conjunction with the MR compatible animal monitoring system (Model 1025, Small Animal Instruments, Inc. Stony Brook, NY.). SCOUT images were taken to verify location, and $\mathrm{T}_{2}$ weighted images for anatomical identification were obtained using an fast spin echo (FSEMS) pulse sequence, with FOV $=40 \times 80(\mathrm{~mm}), 15$ coronal slices, $1 \mathrm{~mm}$ thick, no gap, $\mathrm{T}_{\mathrm{R}}=2450 \mathrm{~s}$, effective $\mathrm{T}_{\mathrm{E}}=72 \mathrm{~ms}$, with fat suppression on. Spectra were obtained using a stimulated echo (STEAM) localization sequence on a $2 \times 2 \times 2.5 \mathrm{~mm}^{3}$ voxel in the bladder with 256 averages (flip angle $90 \mathrm{deg}$, TE 9.44, $\mathrm{T}_{\mathrm{M}}$ 8.01, and TR 2000), for an $8.5 \mathrm{~min}$ acquisition. Images and spectra were processed using the Varian Vnmrj software or using MATLAB (MathWorks, Inc, Natick, MA).

\section{Electrode measurement of $\mathrm{pH}$}

Animals were sedated using isoflurane, and placed on a warming surface to maintain appropriate body temperature for the duration of the experiment. Both the needle microelectrode and the reference electrode were obtained from Microelectrodes, Inc., (Bedford, NH). A shallow small $(<5 \mathrm{~mm})$ incision was made in an alternate (non tumor) site and the $1 \mathrm{~mm}$ reference electrode was placed subcutaneously therein. A needle micro electrode (OD $0.8 \mathrm{~mm}$ with a beveled end) was inserted up to $1.3 \mathrm{~cm}$ into the center of the tumor, and was held in place for up to $1 \mathrm{~min}$, until $\mathrm{pH}$ readings stabilized. The needle was rotated once in each location, to allow the $\mathrm{pH}$ electrode to re-read at the same depth in order to make two independent measurements per location. The $\mathrm{pH}$ was measured at three locations, one near the center/core of the tumor, one in a mid region of the tumor, and one at the rim of the tumor; these values were averaged to report a mean for each animal. After the $\mathrm{pH}$ was measured in the primary tumor, the animals were euthanized (29 days after subcutaneous injection of the primary tumor cells). Before and after the $\mathrm{pH}$ was measured in each animal, the $\mathrm{pH}$ electrodes were used to measure a standard $\mathrm{pH} 7$ buffer solution (Thermo Fisher Scientific, Inc., Waltham, MA).

\section{Statistics}

Non-paired data were analyzed for differences in their mean by two-tailed Student's $t$-test. Chauvenet's criterion was used for outlier analysis of independent data sets. A mouse was rejected from its set based on an expected deviance value of below one-half. The expected deviance 
values for all other physical measurements were above one-half showing two otherwise valid sets [18].

\section{Results}

IEPA is tolerable and orally available

IEPA (Fig. 1a) is a synthetic imadizolic base with a $\mathrm{p} K_{\mathrm{a}}$ of 6.9. When added to drinking water at a concentration of $200 \mathrm{mM}$, mice appear to thrive. The water consumption was not significantly different in the IEPA group compared to that of animals consuming tap water (Fig. 1b). No behavioral alterations were noted and there was no effect on animal weight maintenance or gain (Fig. 1c).

IEPA can be detected in vivo via magnetic resonance spectroscopy, which has been used as a $\mathrm{pH}$ sensitive agent using magnetic resonance spectroscopic imaging, MRSI [17]. Although IEPA is an MRS imaging agent, a $\mathrm{pH}$ electrode was chosen for this experiment in order to avert potential confounding effects of this buffer on the measurement itself. To image $\mathrm{pH}$ with IEPA, it must be given
Fig. 1 a Name and chemical structure of IEPA. b Average water consumption over time in the two cohorts (Tap and IEPA; $n=10$ each) indicating no difference in the amount of water consumption between the treatments. c Average mouse weight over time between cohorts of mice drinking either tap water (Tap) or tap water buffered with $200 \mathrm{mM}$ IEPA (IEPA), showing no significant difference in weight gain or loss between the two treatment groups ( $n=10$ each for tap and IEPA). d T2 weighted coronal image of one mouse which had been drinking IEPA for 2 days. The green square indicates the voxel in the bladder from which the spectrum of IEPA was obtained. e A reference spectrum of $200 \mathrm{mM}$ IEPA obtained at $9.4 \mathrm{~T}$. f Spectrum of IEPA obtained from the bladder (d) showing the same peaks as the reference spectrum, and indicating that the buffered IEPA was absorbed into the blood stream and filtered through the kidneys (rather than being directly excreted through the intestines)
A<smiles>CCOCC(CC(=O)O)n1ccnc1</smiles>

2-imidazol-l-yl-3ethoxycarbonyl propionic acid

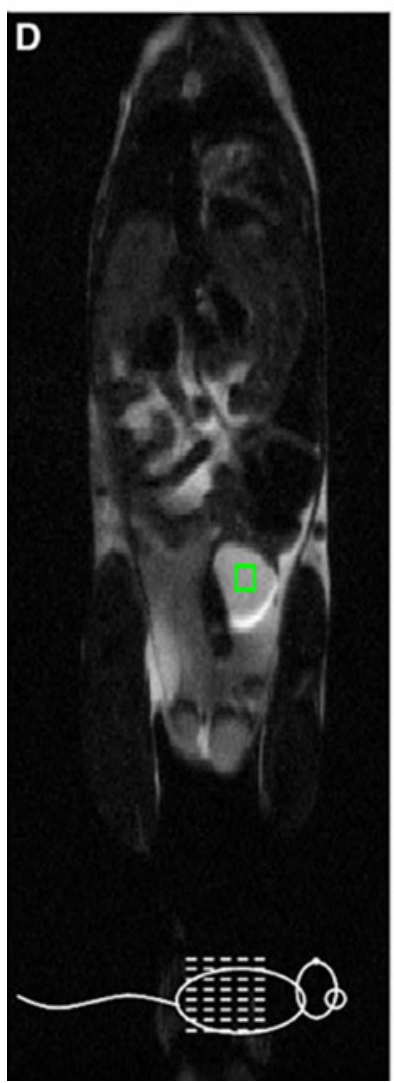

B
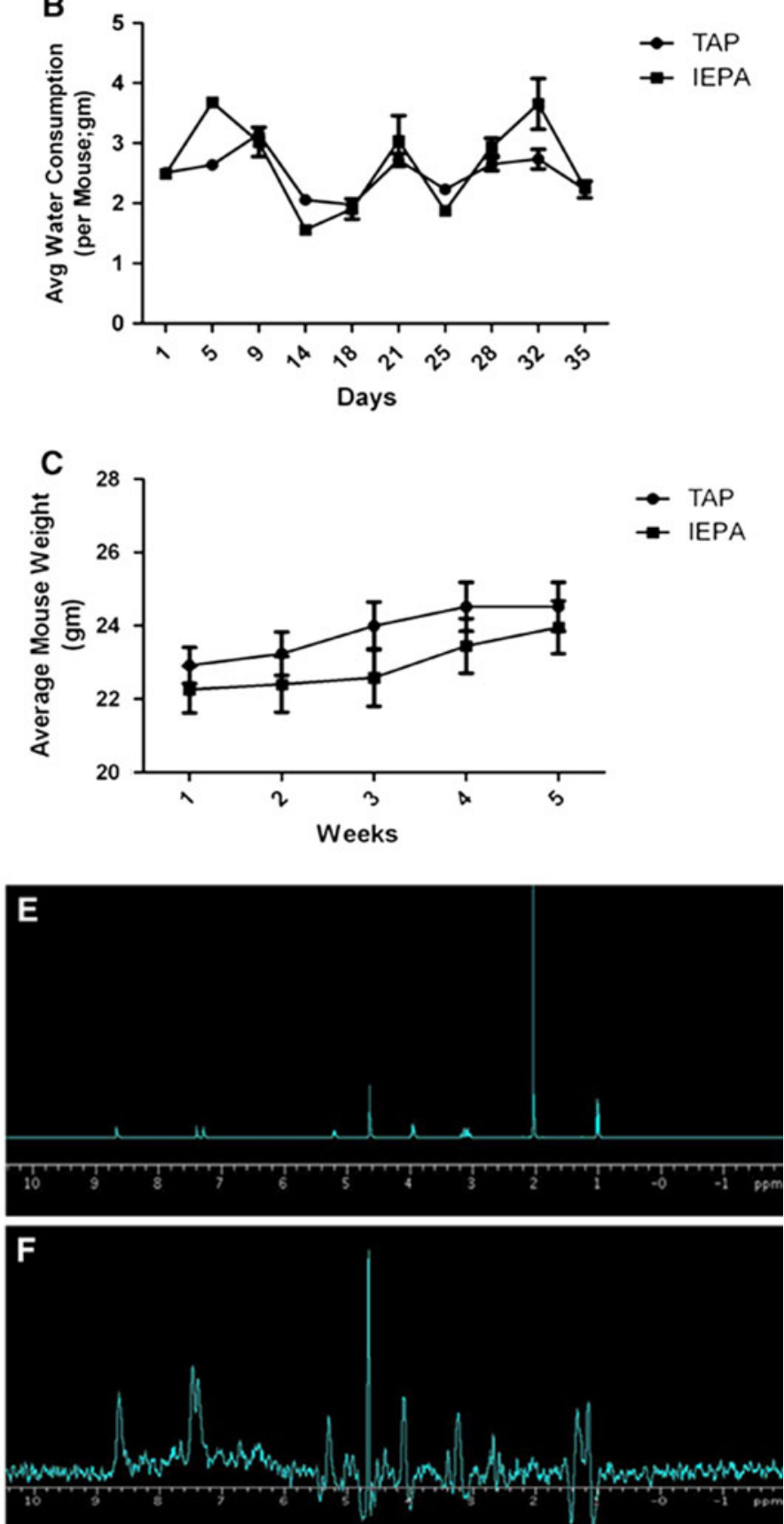
as a bolus and can then be infused intravenously to establish high enough concentrations of IEPA at the site of $\mathrm{pH}$ measurement. Given as a $0.15 \mathrm{ml}$ intraperitoneal bolus injection at $310 \mathrm{mM}$ (as in [17]) this should result in a concentration detectable by MRSI but low enough to have no effect on the $\mathrm{pH}$. However higher steady-state concentrations of IEPA can carry the risk that IEPA itself may alter the $\mathrm{pH}$ that is sought to be measured [19]. Additionally, to measure the $\mathrm{pH}$, IEPA would also have to be infused in the non-treated animals. In order to ensure a distinct separation between treated and untreated animals, IEPA was used only as a buffer and not as an MRSI agent for the purposes of this study.

However, to assess whether ingested IEPA was absorbed into the systemic circulation, MR spectra were obtained from voxels within the bladder of animals that had been drinking IEPA for 2 days. These data showed that there was sufficient IEPA in the bladder (Fig. 1d) to obtain spectra (reference spectrum Fig. 1e, spectrum in bladder Fig. 1f), indicating that it was filtered through the kidneys, and thus was absorbed into the blood stream and systemically available.

Effect of IEPA on PC3M primary tumor growth, $\mathrm{pH}$ and spontaneous metastases

To investigate the effect of IEPA on primary tumor growth, we injected Luciferase expressing prostate cancer cells, PC3M-luc, subcutaneously into the right flank of male SCID mice. Four days prior to injections, half of the animals were provided with $200 \mathrm{mM}$ IEPA in their drinking water. Animals were imaged weekly via bioluminescence. Images from representative animals (Fig. 2a) illustrate growth of the primary tumor in both cohorts of animals. However, the plot of bioluminescence of the primary tumor versus time (Fig. 2b) suggested a trend towards slower tumor growth in the IEPA treated animals. An unpaired two-tailed Students $t$-test, however, showed that these differences did not reach statistical significance $(P \leq 0.06)$.

The tumor $\mathrm{pH}$ was taken immediately prior to euthanasia ( 29 days after injection of the primary tumor), and the tumors were harvested immediately afterwards. The mean tumor $\mathrm{pH}$ for each animal was averaged within each treatment group (tap versus IEPA); and the error was calculated as the standard error between the mean tumor $\mathrm{pH}$ in each group. Tumor $\mathrm{pH}$ measurements showed that, although the effects of IEPA were modest, the $\mathrm{pH}$ values of treated tumors were slightly higher $(P \leq 0.01)$ than that of untreated tumors (Fig. 3a). Acidosis can induce both necrosis and apoptosis [20, 21]. Hence, in this system, we investigated whether IEPA treated tumors exhibited altered levels of cell death. Necrosis of the primary tumor were studied by H\&E staining and counted by area, as outlined
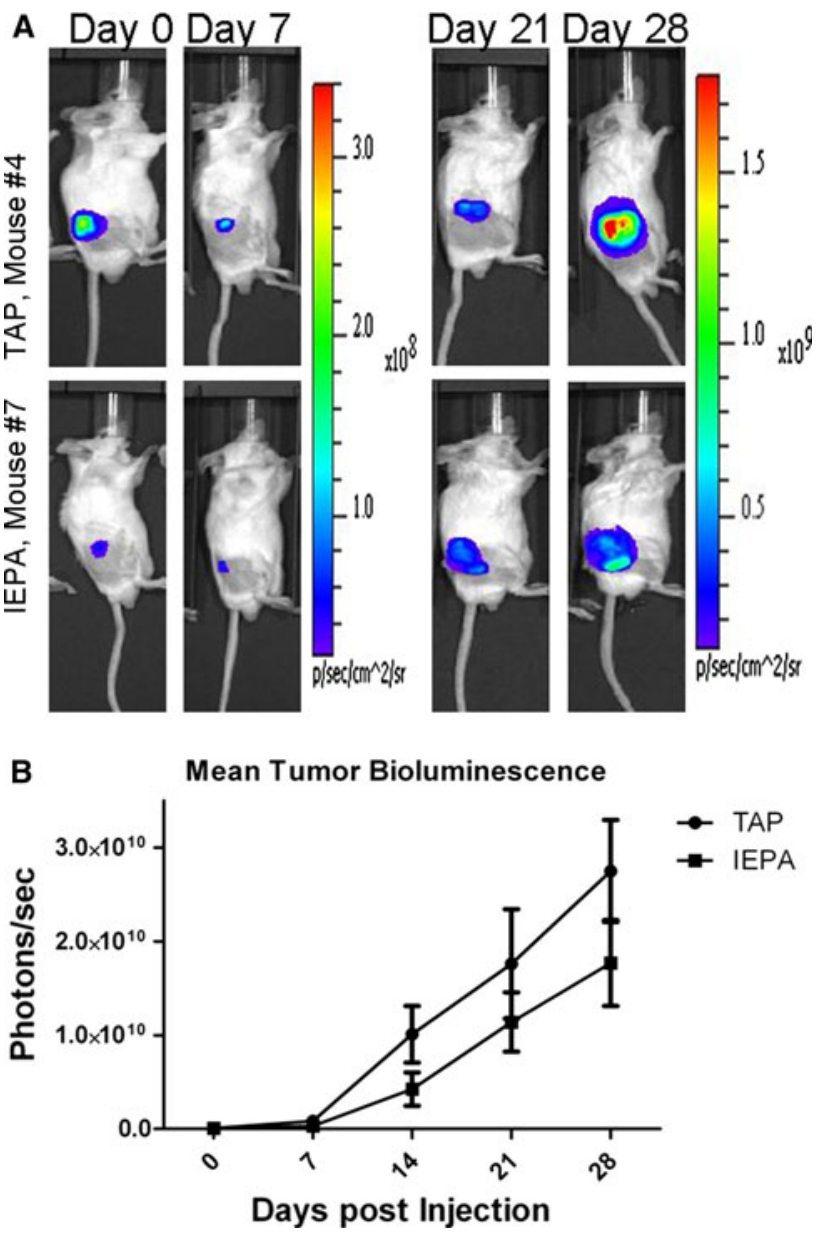

Fig. 2 a Representative bioluminescence images of one mouse from each cohort (Tap vs. IEPA) at days $0,7,21$ and 28 post subcutaneous injection of luciferase expressing PC $3 \mathrm{M}$ prostate cancer cells. b Mean tumor bioluminescence of each cohort ( $n=5$ each) plotted versus time post injection showing an increase in bioluminescence with time for both groups

in Methods. The results of this analysis are shown in Table 1. Sample histological images are shown in Fig. 3b (Tap) and c (IEPA). These data indicate that the IEPAtreated tumors exhibited significantly less necrosis than controls (Fig. 3d; $P \leq 0.05$ ).

Metastasis is a process that includes a series of distinct steps starting with penetration of cancer cells through the basement membrane; local invasion into the surrounding tissue; intravasation to lymphatic or blood then extravasation and colonization in a new host organ [22]. To study the effect of IEPA on the entire metastasis paradigm, bioluminescent images were obtained from the thoracic regions of each cohort (IEPA vs. tap) of animals beginning 3 weeks after subcutaneous injection to form the primary tumor. These images were obtained in addition to the whole-body bioluminescence imaging which was used to monitor primary tumor growth. Because the primary tumors were much larger than the metastases, and therefore 

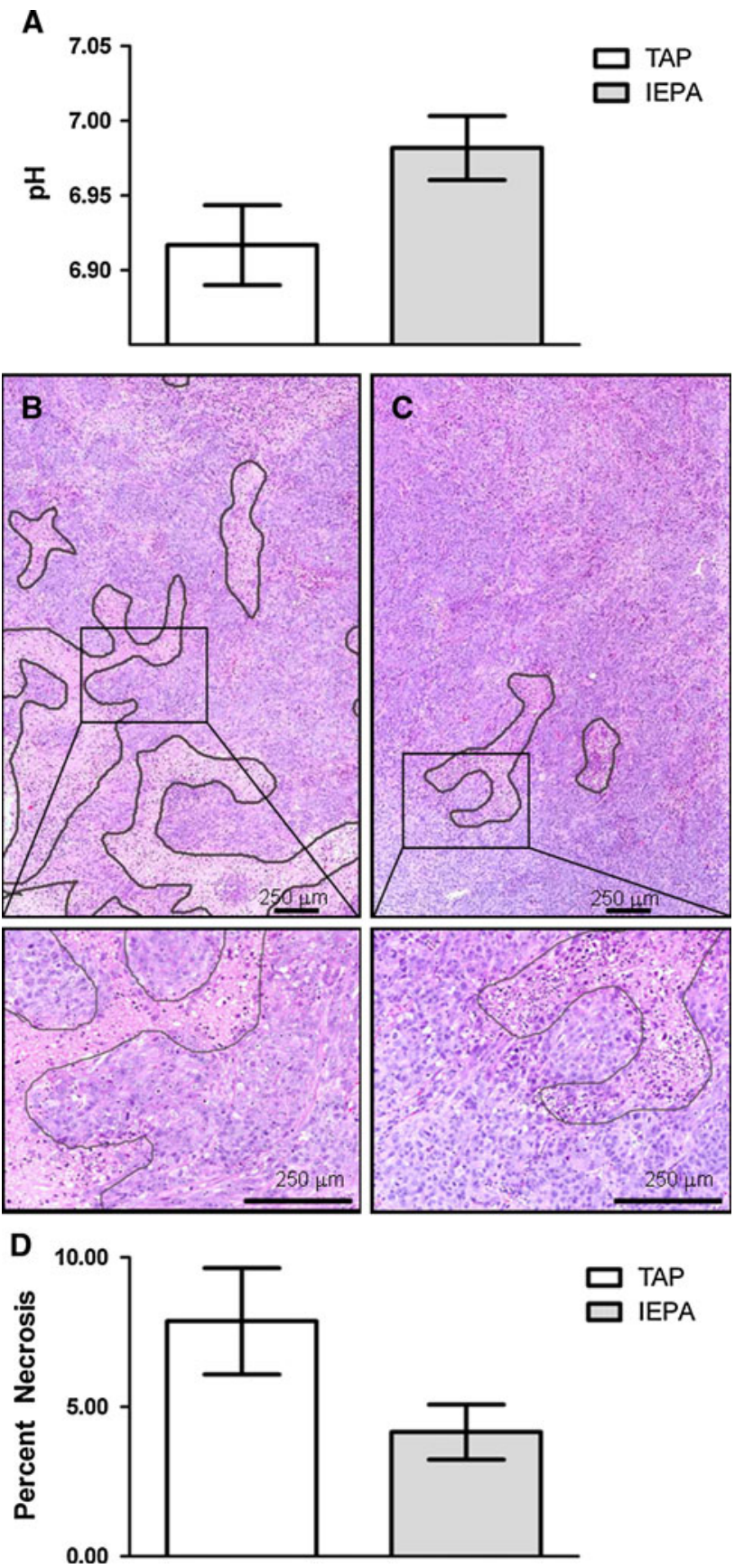

Fig. 3 a The average $\mathrm{pH}$ of the tumors (prior to excision) for each cohort, showing a higher $\mathrm{pH}$ in the IEPA animals (Error bars represent SEM within each group; $n=5$ for both IEPA and tap). $\mathrm{H} \& \mathrm{E}$ results from representative tumors from $\mathbf{b}$ mouse 4-TAP and c mouse 7-IEPA. d The average percent necrosis for each cohort, showing a larger necrotic portion in the TAP animals

had larger signals, the primary tumors were covered with opaque material during the lung imaging sessions. The thoracic region was imaged because the lungs are known to be one of the primary sites of metastases for this tumor model. Through these in vivo measurements, the thoracic region in the IEPA cohort was observed to have
Table 1 The results of analysis after immunohistological staining with hematoxylin and eosin

\begin{tabular}{llrrc}
\hline Sample ID & Treatment & $\begin{array}{l}\text { Necrotic } \\
\text { tissue } \\
\text { area }\end{array}$ & Total area & $\begin{array}{l}\text { Percent } \\
\text { necrotic } \\
\text { tissue }(\%)\end{array}$ \\
\hline Tumor 1 & TAP & 2276923 & 113437268 & $\mathbf{2 . 0 1}$ \\
Tumor 2 & TAP & 11281434 & 91144941 & $\mathbf{1 2 . 3 8}$ \\
Tumor 3 & TAP & 5367952 & 88603533 & $\mathbf{6 . 0 6}$ \\
Tumor 4 & TAP & 4919959 & 53834343 & $\mathbf{9 . 1 4}$ \\
Tumor 5 & TAP & 5150663 & 52828414 & $\mathbf{9 . 7 5}$ \\
Tumor 6 & IEPA & 1534073 & 103888541 & $\mathbf{1 . 4 8}$ \\
Tumor 7 & IEPA & 5354162 & 106898694 & $\mathbf{5 . 0 1}$ \\
Tumor 8 & IEPA & 5483978 & 85612363 & $\mathbf{6 . 4 1}$ \\
Tumor 9 & IEPA & 2520735 & 99570341 & $\mathbf{2 . 5 3}$ \\
Tumor 10 & IEPA & 1408415 & 26232504 & $\mathbf{5 . 3 7}$ \\
\hline
\end{tabular}

The total area and the necrotic portion were quantitatively measured resulting in the percent necrosis (as shown in bold)

significantly fewer metastases compared to controls at 28 days (Fig. $4 ; P \leq 0.02$ ). Thus, although IEPA did not have a significant effect on primary tumor growth, it did reduce the numbers of spontaneous metastases in this system.

IEPA reduces experimental metastasis

The above data indicate that IEPA reduces spontaneous metastases, which involves both intravasation and extravasation, with only a moderate, non-significant effect on the primary tumor. This is consistent with previous studies using bicarbonate [13]. Because the effects of these buffers were limited mainly to the metastases, we then investigated whether IEPA affected the efficiency of extravasation and colonization with an experimental metastases model, wherein PC3M cells were injected directly into the tail vein of mice consuming either $200 \mathrm{mM}$ IEPA or tap water. The results (Fig. 5) showed that IEPA led to a significant decrease in the appearance of lung metastases for up to 6 weeks after injection. These findings indicate that IEPA significantly inhibited extravasation and or colonization in this experimental metastases model with PC $3 \mathrm{M}$ cells. After 6 weeks there were approximately $1 \times 10^{8}$ photons $/ \mathrm{sec}$ from the control mice and only ca. $3 \times 10^{6}$ photons/sec emanating from the thoracic area of mice treated with IEPA $(P \leq 0.002)$.

\section{Discussion}

Previous work has shown that a volatile buffer, i.e. bicarbonate, was effective in inhibiting spontaneous and experimental metastases [13]. The aim of the current study 

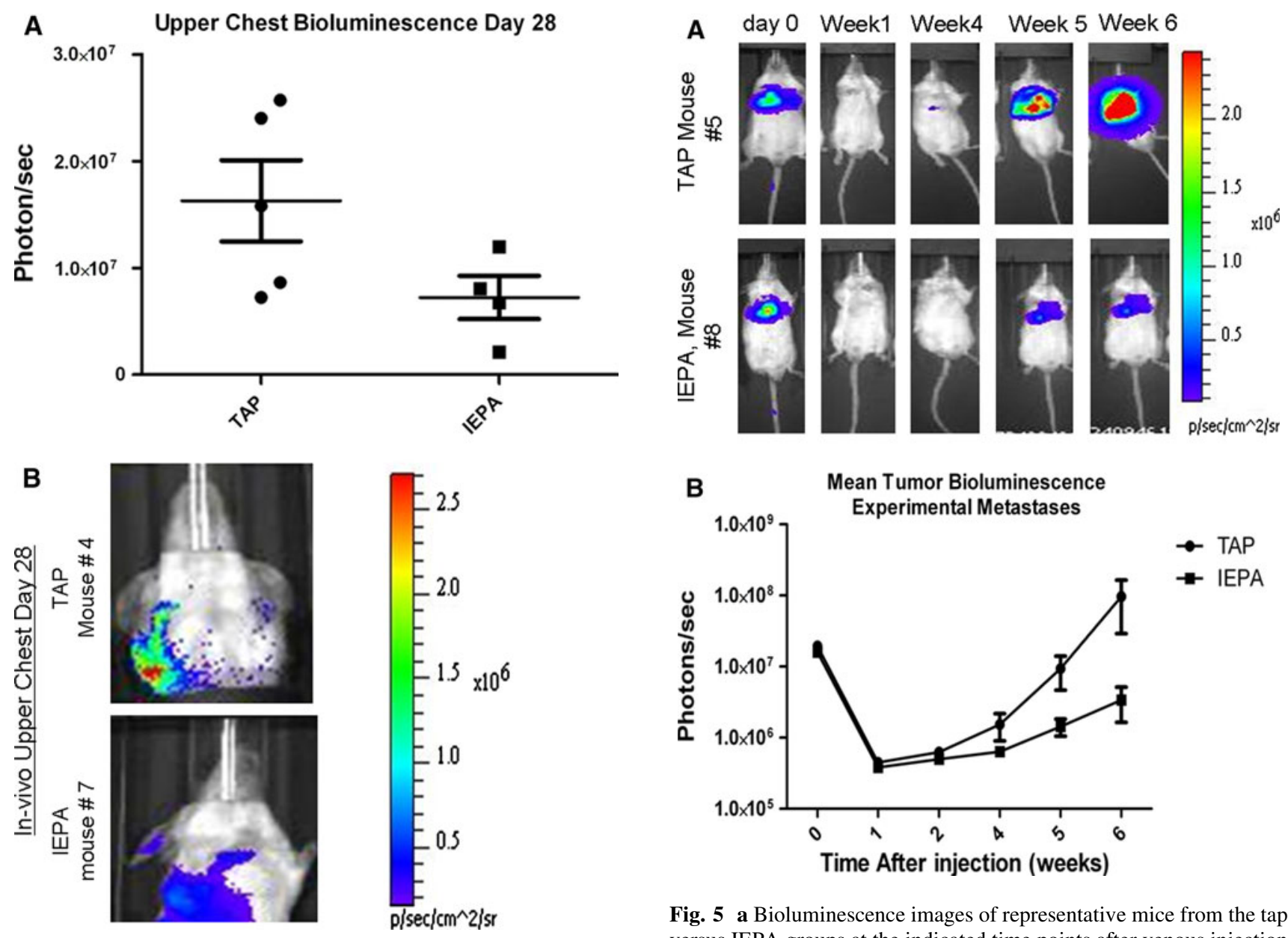

Fig. 4 a The in vivo bioluminescence of the thoracic area for each group of mice with subcutaneous PC3M tumors. b The in vivo bioluminescence images of the upper chest area for one representative mouse from each group

was to investigate the effects of non-volatile buffers, specifically IEPA, to test the hypothesis that metastases inhibition was due to buffering and was not specific to bicarbonate. Metastasis is the leading cause of death from cancer [23] and can be promoted by low $\mathrm{pH}$ and acidity; which is a common feature of solid tumors. The extracellular $\mathrm{pH}(\mathrm{pHe})$ of solid tumor is acidic, e.g. $\mathrm{pHe}$ of 6.5-7.1, compared to normal tissues with a pHe of 7.3-7.4. Experimental observations have shown that acid-mediated invasion can occur via destruction of the extracellular matrix, which is promoted by proteases and glycosidases and may convert in situ to locally invasive cancers [29]. An 'acid-mediated invasion hypothesis' was developed using mathematical models supported by empirical observations [14], and states that: (1) tumors export $\mathrm{H}^{+}$into the adjacent stroma; (2) this results in damage to supporting stroma accompanied by cell death and extracellular matrix (ECM) break down; which (3) facilitates the invasion of the tumor cells and consequently colonization at distant sites. As a

Fig. 5 a Bioluminescence images of representative mice from the tap versus IEPA groups at the indicated time points after venous injection of luciferin expressing PC3M cancer cells to induce experimental metastases. b Mean tumor bioluminescence in each group after induction of experimental metastases, indicating fewer metastases in the IEPA cohort than in the Tap (note log scale)

test of the model we observed that chronic oral administration of sodium bicarbonate $\left(\mathrm{NaHCO}_{3}\right)$, a physiologic buffer, was able to increase tumor pHe and reduce lung metastasis in spontaneous and experimental breast and prostate animal models. Neutralization of tumor acidity was measured with fluorescence microscopy of a dorsal window chamber and ${ }^{31} \mathrm{P}$ magnetic resonance spectroscopy. Even though $\mathrm{NaHCO}_{3}$ was effective and inexpensive, its $\mathrm{p} K_{\mathrm{a}}$ may be lower than optimal, and it was unclear whether it was working as a buffer, or if the effect was specific for bicarbonate. Therefore, in this study we examined a non-volatile buffer with a higher $\mathrm{p} K_{\mathrm{a}}$ value for its effects on spontaneous metastasis.

We used IEPA with $\mathrm{p} K_{\mathrm{a}} \sim 7$, and the PC3M prostate cancer cell line was chosen because, as shown in our previous work, it was responsive to bicarbonate. IEPA was shown to be absorbed into the blood stream, and had no negative effects on the animal's growth or behavior. In a subcutaneous tumor model, we found that IEPA only 
slightly decreased the growth rate of the primary tumor. However this decrease in size was accompanied with a small but significant increase in the primary tumor $\mathrm{pH}$ and a substantial change in tumor anatomy; with a lower percentage necrosis when compared to control animals.

Although bone marrow is the most common site for prostate cancer metastasis, it is also known to metastasize to the lungs [24]. Spontaneous metastases, as measured by in vivo upper thoracic bioluminescence, were decreased in the IEPA-treated animals. Experimental metastases following tail vein injection were measured by total and thoracic in vivo bioluminescence, and these were also substantially decreased in the IEPA-treated animals. Hence, this non-volatile buffer was effective in reducing spontaneous and experimental metastases, compared to bicarbonate. This suggests that the effect is due to $\mathrm{pH}$ buffering and is not due to a specific bicarbonate effect per se. The fact that both spontaneous and experimental metastases were inhibited also suggests that the effect of the buffer therapy is on extravasation or/and colonization and not intravasation.

To investigate if the increase in tumor $\mathrm{pH}$ could be responsible for the remarkable decrease in metastases, we used the subcutaneous (spontaneous) model to measure the $\mathrm{pH}$ of the primary tumor. We observed a slight (statistically significant) increase in the primary tumor $\mathrm{pH}$ with IEPA treatment, accompanied by a substantial decrease in necrotic tumor anatomy. Although statistically significant, the change in $\mathrm{pHe}$ of the primary tumor was very slight (0.06 pH units) and the physiological relevance of this change is unclear. In work with other tumor models, we have observed that the effect of bicarbonate on tumor $\mathrm{pH}$ was reduced in large and/or rapidly metabolizing tumors (data not shown). The slight effects seen in this system are also consistent with reaction-diffusion models, which also predict that a larger and more substantial effect may take place at the site of colonization, when tumors are small (ca. $1 \mathrm{~mm}$ ) and poorly perfused [14]. Unfortunately, no methods are available that can measure the pHe of these small nascent colonies. Thus, we propose that the major effect of buffering occurs at metastatic sites, where acid load is lower due to smaller foci and where reducing acidity can inhibit local invasion [25-27].

Several mechanisms could potentially contribute to the effect of buffers on tumor metastasis. Angiogenic factors, such as vascular endothelial growth factor (VEGF-A) and interleukin 8 (IL-8) are upregulated by acidic pHe [28]. Neovascularization influences the dissemination of cancer cells throughout the body ultimately leading to metastasis formation. IEPA may possibly function through increasing pHe thereby affecting angiogenesis and consequently metastasis. The acid-mediated invasion can occur via destruction of the extracellular matrix, which is promoted by proteases and glycosidases and may convert in situ to locally invasive cancers [29]. Matrix metalloproteinases (MMP-2 and MMP-9) are believed to be critical for invasion. Even tough the MMPs have alkaline $\mathrm{pH}$ optima, low $\mathrm{pH}$ will increase their activation and release $[11,30]$. Lysosomal proteases (cathepsins) are more active at acid $\mathrm{pH}$, are released in invasive cancers, and function to proteolytically activate MMPs [31]. Thus, it is possible that the buffers, by neutralizing tumor acidosis, are decreasing the proteolytic enzyme activation and prevent the ECM degradation which leads to decrease metastasis.

In summary significant reduction of metastasis with IEPA buffer support the hypothesis that non-volatile buffers with $\mathrm{p} K_{\mathrm{a}} \geq 7$ should be more effective in buffering extra cellular acidity [14]. This study specifically used prostate cancer model PC3M because in our previous work we have shown that this model was highly responsive to bicarbonate treatment. Previous work has shown that bicarbonate was ineffective in inhibiting metastases from B16 melanoma. These cells are more metabolically active and produce $\mathrm{H}^{+}$at a higher rate, compared to PC3M (data not shown) and hence, we hypothesize that they may be inhibitable with more buffering power, such as that of nonvolatile buffers.

These findings suggest that non-volatile buffers, such as imidazoles may have the potential for clinical benefit. Sodium bicarbonate is currently in two clinical trials as a buffer; however compliance is low because of the taste. Thus, there is a need to find a palatable and effective alternative. The current work shows evidence that other buffers may be considered as an alternative to the $\mathrm{NaHCO}_{3}$ in clinical trials with the possibility of better tolerance in addition to greater efficacy. This study indicated no toxicity in mouse models, in agreement with previous findings $[32,33]$. Additionally, the measurements performed in the study by Garcia Martin et al. [15] indicate that the IEPA was able to extravasate only in the areas of the brain affected by the glioma and not in normal brain. Thus IEPA is not expected to cross the normal blood brain barrier within detectable limits.

In conclusion, this study demonstrates that a non-volatile buffer can reduce the incidence and growth of experimental metastases in a model of prostate cancer. Previous work using buffer therapy has exclusively used bicarbonate, which may act through alternative pathways, e.g. through activation of carbonic anhydrases. The current work demonstrates that alternative, non-volatile buffers can be equally efficacious as bicarbonate. Thus the mechanism of metastasis inhibition appears to be limited to $\mathrm{pH}$ buffering. It also introduces alternative buffers that may be more applicable in a clinical setting for acute or chronic use. 
Open Access This article is distributed under the terms of the Creative Commons Attribution Noncommercial License which permits any noncommercial use, distribution, and reproduction in any medium, provided the original author(s) and source are credited.

\section{References}

1. Griffiths JR (1991) Are cancer cells acidic? Br J Cancer 64(3): 425-427

2. Bhujwalla ZM, Constantinidis I, Chatham JC et al (1992) Energy metabolism, $\mathrm{pH}$ changes, and lactate production in RIF-1 tumors following intratumoral injection of glucose. Int $\mathbf{J}$ Radiat Oncol Biol Phys 22(1):95-101

3. Vaupel P, Kallinowski F, Okunieff P (1989) Blood flow, oxygen and nutrient supply, and metabolic microenvironment of human tumors: a review. Cancer Res 49(23):6449-6465

4. Rofstad EK (2000) Microenvironment-induced cancer metastasis. Int J Radiat Biol 76(5):589-605

5. Stubbs M, McSheehy PM, Griffiths JR et al (2000) Causes and consequences of tumour acidity and implications for treatment. Mol Med Today 6(1):15-19

6. Campo E, Munoz J, Miquel R et al (1994) Cathepsin B expression in colorectal carcinomas correlates with tumor progression and shortened patient survival. Am J Pathol 145(2):301-309

7. Rochefort H, Garcia M, Glondu M et al (2000) Cathepsin D in breast cancer: mechanisms and clinical applications, a 1999 overview. Clin Chim Acta Int J Clin Chem 291(2):157-170

8. Rochefort H, Liaudet-Coopman E (1999) Cathepsin D in cancer metastasis: a protease and a ligand. APMIS 107(1):86-95

9. Rozhin J, Sameni M, Ziegler G et al (1994) Pericellular $\mathrm{pH}$ affects distribution and secretion of cathepsin $\mathrm{B}$ in malignant cells. Cancer Res 54(24):6517-6525

10. Martinez-Zaguilan R, Seftor EA, Seftor RE et al (1996) Acidic $\mathrm{pH}$ enhances the invasive behavior of human melanoma cells. Clin Exp Metastasis 14(2):176-186

11. Rofstad EK, Mathiesen B, Kindem K et al (2006) Acidic extracellular $\mathrm{pH}$ promotes experimental metastasis of human melanoma cells in athymic nude mice. Cancer Res 66(13):6699-6707

12. Schlappack OK, Zimmermann A, Hill RP (1991) Glucose starvation and acidosis: effect on experimental metastatic potential, DNA content and MTX resistance of murine tumour cells. Br J Cancer 64(4):663-670

13. Robey IF, Baggett BK, Kirkpatrick ND et al (2009) Bicarbonate increases tumor $\mathrm{pH}$ and inhibits spontaneous metastases. Cancer Res 69(6):2260-2268

14. Silva AS, Yunes JA, Gillies RJ et al (2009) The potential role of systemic buffers in reducing intratumoral extracellular $\mathrm{pH}$ and acid-mediated invasion. Cancer Res 69(6):2677-2684

15. Garcia-Martin ML, Herigault G, Remy C et al (2001) Mapping extracellular $\mathrm{pH}$ in rat brain gliomas in vivo by $1 \mathrm{H}$ magnetic resonance spectroscopic imaging: comparison with maps of metabolites. Cancer Res 61(17):6524-6531
16. Gillies RJ, Raghunand N, Karczmar GS et al (2002) MRI of the tumor microenvironment. J Magn Reson Imaging 16(4):430-450

17. van Sluis R, Bhujwalla ZM, Raghunand N et al (1999) In vivo imaging of extracellular $\mathrm{pH}$ using $1 \mathrm{H}$ MRSI. Magn Reson Med 41(4):743-750

18. Taylor JR (1997) An introduction to error analysis: the study of uncertainties in physical measurements. University Science Books, Mill Valley

19. Raghunand $\mathrm{N}$ (2006) Tissue $\mathrm{pH}$ measurement by magnetic resonance spectroscopy and imaging. In: Prasad P (ed) Magnetic resonance imaging: methods and biologic applications. Humana Press, Totowa, pp 347-364

20. Williams AC, Collard TJ, Paraskeva C (1999) An acidic environment leads to p53 dependent induction of apoptosis in human adenoma and carcinoma cell lines: implications for clonal selection during colorectal carcinogenesis. Oncogene 18(21): 3199-3204

21. Ding D, Moskowitz SI, Li R et al (2000) Acidosis induces necrosis and apoptosis of cultured hippocampal neurons. Exp Neurol 162(1):1-12

22. Fidler IJ (2003) The pathogenesis of cancer metastasis: the 'seed and soil' hypothesis revisited. Nat Rev 3(6):453-458

23. Weigelt B, Peterse JL, van't Veer LJ (2005) Breast cancer metastasis: markers and models. Nat Rev 5(8):591-602

24. Bubendorf L, Schopfer A, Wagner U et al (2000) Metastatic patterns of prostate cancer: an autopsy study of 1,589 patients. Hum Pathol 31(5):578-583

25. Gillies RJ, Gatenby RA (2007) Adaptive landscapes and emergent phenotypes: why do cancers have high glycolysis. J Bioenerg Biomembr 39(3):251-257

26. Moellering R, Black K, Krishnamurty C et al (2008) Acid treatment of melanoma cells selects for invasive phenotypes. Clin and Exp Metastasis 25(4):411-425

27. Fang JS, Gillies RJ, Gatenby RA (2008) Adaptation to hypoxia and acidosis in carcinogenesis and tumor progression. Semin Cancer Biol 18(5):330-337

28. Karashima T, Sweeney P, Kamat A et al (2003) Nuclear factorkappaB mediates angiogenesis and metastasis of human bladder cancer through the regulation of interleukin-8. Clin Cancer Res 9(7):2786-2797

29. Hanahan D, Weinberg RA (2000) The hallmarks of cancer. Cell 100(1):57-70

30. Sounni NE, Noel A (2005) Membrane type-matrix metalloproteinases and tumor progression. Biochimie 87(3-4):329-342

31. Sloane BF, Moin K, Krepela E et al (1990) Cathepsin B and its endogenous inhibitors: the role in tumor malignancy. Cancer Metastasis Rev 9(4):333-352

32. van Sluis R, Bhujwalla ZM, Raghunand N, et al (1998) Imaging of extracellular $\mathrm{pH}$ using $1 \mathrm{H}$ MRSI. In: Proceedings of the ISMRM 6th annual meeting, Sydney p 1642

33. Gillies RJ, Raghunand N, Bhujwalla ZM, et al (1997) Measurement of extracellular $\mathrm{pH}$ in tumors by $1 \mathrm{H}$ MRSI. In: Proceedings of the ISMRM 5th annual meeting, Vancouver, p 1099 